\title{
O IMPACTO DAS TECNOLOGIAS DISRUPTIVAS NO MERCADO DE TRABALHO E O DEVER DO ESTADO
}

\author{
Sabrinna Araújo Almeida Lima ${ }^{1}$ \\ André Studart Leitão*
}

\section{RESUMO}

Com o advento de tecnológico, a sociedade está em evolução. Profissões serão executadas por robôs. Diante desse cenário, analisar-se-á o papel do Estado no âmbito trabalhista, econômico e social. O artigo visa demonstrar o impacto tecnológico no mundo do trabalho, ponderando as transformações ao longo dos anos. A justificativa decorre da importância da temática para a sociedade, visto a violação a direitos fundamentais. Conclui-se que o papel do Estado é normalizar as relações sociais por meio de políticas públicas de proteção ao trabalhador. Utilizaram-se a metodologia descritiva e bibliográfica e fontes físicas e virtuais.

Palavras-chave: Tecnologias Disruptivas; Mercado de Trabalho; Impactos; Sociedade

\section{THE IMPACT OF DISRUPTIVE TECHNOLOGIES ON THE LABOR MARKET AND THE DUTY OF THE STATE}

\begin{abstract}
With the advent of technology, society is evolving. Professions will be performed by robots. In this scenario, the role of the State in the labor, economic and social spheres will be analyzed. The article aims to demonstrate the technological impact on the world of work, considering the changes over the years. The justification stems from the importance of the theme for society, given the violation of fundamental rights. It is concluded that the role of the State is to normalize social relations through public policies to protect workers. Descriptive and bibliographic methodology and physical and virtual sources were used.
\end{abstract}

Keywords: Disruptive Technologies; Labor market; Impacts; Society

\section{INTRODUÇÃO}

Há uma estimativa de que, estar-se-á vivenciando uma nova revolução industrial, definida como Revolução 4.0, o que revela ser um processo de consideráveis mudanças na seara tecnológica afetando diretamente as relações de trabalho e, consequentemente, as

\footnotetext{
${ }^{1}$ Bacharel em Direito pela Faculdade Luciano Feijão, Pós-Graduada em Direito e Processo do Trabalho e em Direito Previdenciário pelo Centro Educacional Damásio de Jesus e Mestranda em Direito pelo Centro Universitário Christus - UNICHRISTUS. Endereço Eletrônico: sabrinnalima_@ hotmail.com.

${ }^{* *}$ Mestre e Doutor em Direito (PUC-SP). Pós-doutor em Direito (Universidade Presbiteriana Mackenzie e Universidade de Fortaleza). Pós-doutorando em Direito pelo Mediterranea International Centre for Human Rights Research. Professor no Programa de Pós-Graduação em Direito da Unichristus. Professor no curso de graduação em Direito da FBUni. Procurador Federal. E-mail: andrestudart@ gmail.com.
} 
relações econômicas e sociais. Como exemplo, tem-se a adoção da inteligência artificial no âmbito empresarial e carros autônomos.

A principal e preocupante consequência desse advento é o fato de possível extinção de cargos e funções e até mesmo a substituição da mão de obra humana por robôs. Isso poderá ocorrer pois o implemento dessas tecnologias podem acarretar um maior custo-benefício para o empresariado, qual seja, menor custo e maior eficácia e executoriedade, produtividade em menor lapso temporal e mais lucros.

Partindo dessa premissa, diante de uma eminente crise de desemprego e impactos sociais, o Estado tem o dever de reorganizar a sociedade, a economia e o mercado de trabalho frente as exigências que a era tecnológica impõe. Tal fato é uma realidade em decorrência de algumas transformações já estarem presentes em nosso dia a dia.

Por isso, o presente artigo traz uma percepção dos impactos das tecnologias disruptivas no mercado de trabalho, verificando as transformações ocorridas ao longo dos anos diante da efetivação de tecnologias não evolucionárias e como tais implementações abalam o âmbito laboral, econômico e social. Ainda, apresenta o que seria o dever do Estado quanto a temática visando o equilíbrio entre essa revolução tecnológica e a proteção ao trabalhador.

Frente a isso, este artigo tem como objetivo responder as seguintes indagações: Quais os impactos que as tecnologias disruptivas causam na sociedade, atingindo além do âmbito social, o econômico e o laboral? Os direitos fundamentais sociais inerentes ao homem restam violados nessa nova era? Qual seria o dever do Estado diante do iminente colapso social ocasionado pelo advento tecnológico?

Dado os pontos abordados nessa temática refletirem diretamente na vida dos trabalhadores brasileiros, verifica-se uma real importância desta pesquisa para a sociedade, estando demonstrada na relevância de debater e divulgar os direitos fundamentais de proteção, valor social do trabalho do homem e implementação da integridade social inerentes a todos os trabalhadores. Acrescenta-se ainda que, para o meio acadêmico, a significância desse artigo apresenta-se pelo desenvolvimento de bibliografia sobre o tema, tal como o estímulo ao debate no intuito de instigar mais pesquisas nessa esfera. 
Adotou-se para a realização desse artigo o tipo de pesquisa descritiva e bibliográfica, dado que este artigo busca apresentar como o assunto vem sendo desenvolvido pelos doutrinadores, estudiosos e acadêmicos através de livros, artigos científicos, notícias, dentre outros meios. Bem como fora realizada uma pesquisa qualitativa buscando interpretar os fenômenos em discussão.

Foram utilizadas fontes físicas e virtuais que abordem sobre o assunto e fora realizada uma abordagem dialética, pelo confronto das teorias, informações e dados alcançados durante a pesquisa, no intuito de formar convicção do que em melhor conformidade se encontra com os direitos fundamentais sociais e humanos dos trabalhadores brasileiros.

Este trabalho organizar-se-á da seguinte forma: a) evolução histórica, fazendo uma abordagem de como as tecnologias disruptivas vieram sendo empregadas ao longo dos anos; b) tecnologias disruptivas e seus reflexos, abrangendo principalmente a seara econômica, social e laboral; c) o dever do Estado, abordando quais seriam as possíveis soluções preventivas a serem adotadas a fim de evitar a violação dos direitos fundamentais de proteção ao trabalhador; d) conclusões tomadas durante a pesquisa.

\section{EVOLUÇÃO HISTÓRICA}

Ao pensar em tecnologia disruptiva associa-se a algo futurístico, algo a ser aprimorado. Ocorre que a disrupção está presente na sociedade há milhares de anos. É possível visualizar tal fenômeno quando o homem extraía da natureza somente o essencial para sua subsistência, daí demonstrase-se disrupção ao fato que o homem abandonou a caça por seu alimento e passou a cultivá-lo e criá-lo. Dito isso, Yuval Noah Harari $(2018$, p. 87) relata o início das disrupções na vida do homem, a chamada Revolução Agrícola:

Tudo isso mudou há cerca de 10 mil anos, quando os sapiens começaram a dedicar quase todo seu tempo e esforço a manipular a vida de algumas espécies de plantas e animais. Do amanhecer ao entardecer, os humanos espalhavam sementes, aguavam plantas, arrancaram ervas daninhas do solo e conduziam ovelhas a pastos escolhidos. Esse trabalho, pensavam, forneceria mais frutas, grãos e carnes. Foi uma revolução a maneira como os humanos viviam - a Revolução Agrícola (HARARI, 2018, p. 87).

À visto disso, em segundo plano e ao avançar tecnológico e descontinuidades da modernidade, outros diversos exemplos vivenciados ao passar do tempo podem ser citados, 
como a utilização de carros substituindo carroças, a extinção de máquinas de datilografia por computadores e a utilização do relógio mecânico como mecanismo de desencaixe entre tempo e espaço (GIDDENS, 1990, p. 24).

O segundo marco histórico de mudanças e consequências no âmbito social, econômico e laboral, em virtude da abrangência de transformações concretas e irreversíveis foi a chamada Revolução Industrial. Essa evolução descontínua foi marcada pela introdução de maquinário, indústria e matéria prima na esfera de produção, descaracterizando significativamente a estruturação de trabalho do homem, uma vez que os recém-chegados ao mundo dos "modernos" experimentam aquela "separação entre o lar e a empresa" (BAUMAN, 2007, p. 39). Logo, seu local de trabalho deixou de ser seu lar e passou a ser uma fábrica, e sua criação deixou de ser manual e passou a ser mecanizada.

Nas palavras de Zedequias Vieira Cavalcante e Mauro Luis Siqueira Silva (2011, online), a Revolução Industrial é descrita de maneira a abordar suas substanciais transformações à época:

A Revolução Industrial vai além da idéia de grande desenvolvimento dos
mecanismos tecnológica aplicados à produção, na medida em que: consolidou o
capitalismo; aumentou de forma rapidíssima a produtividade do trabalho; originou
novos comportamentos sociais, novas formas de acumulação de capital, novos
modelos políticos e uma nova visão do mundo; e talvez o mais importante,
contribuiu de maneira decisiva para dividir a imensa maioria das sociedades
humanas em duas classes sociais opostas e antagônicas: a burguesia capitalista e o
proletariado. (CAVALCANTE; SILVA, 2011, online).

Mesmo centenas de anos atrás, a adoção tecnologias disruptivas acarretou diversos impactos severos sociais, econômicos e laborais. Com o implemento do maquinário dos meios de produção, a mão de obra humana tornou-se cada vez mais desvalorizada, e trabalhadores não tinham garantias, tornando-os cada vez mais fragilizados nessa relação. O labor humano depreciou-se ao ponto de atingir ao patamar da exploração de trabalho infantil. Nesse sentido, Cesar Sanson (2009, p. 08):

\footnotetext{
A Revolução Industrial altera substancialmente o conteúdo e a forma de organização do trabalho humano e anuncia uma nova realidade: a sociedade industrial. A sociedade industrial instaura uma nova forma de produzir, opondo os proprietários dos meios de produção - fábricas, máquinas e matéria-prima - aos trabalhadores, aqueles que dispõem apenas de sua força de trabalho. A relação entre os proprietários dos meios de produção e os trabalhadores que vendem a sua força de trabalho institui o assalariamento, base do modo de produção capitalista, descrito por Marx [...] (SANSON, 2009, p. 08).
} 
Uma era marcada por tormentos, a modernidade tem também um lado sombrio (GIDDENS, 1990, p. 13). Porém, apesar de ter sido um período em que acarretou sequelas sociais irreversíveis em virtude das intensas alterações no trabalho do homem, todas as Revoluções Industriais desempenharam um papel essencial para o desenvolvimento da sociedade.

Uma nova forma de produzir foi instituída e novas fontes de energia foram implementadas. Com o advento da eletricidade tornou-se possível o lançamento de novas tecnologias, produtos e máquinas, como o telefone, televisores, carros e avião. Tais tecnologias possibilitaram otimizar a comunicação, diminuindo distancias, servindo como mecanismos de desencaixe para separação entre tempo e espaço, crucial para o extremo dinamismo da modernidade (GIDDENS, 1990, p. 23).

Com isso, a informação e o conhecimento passaram a ser o marco da era pósindustrial, uma era na qual ocorreu uma reorganização do trabalho do homem e a inserção da mulher na sociedade. Houve a harmonização do implemento das tecnologias e o trabalho na produção. Nesse sentido, Isabel Carvalho e Ana Lúcia Kaniski (2000, p. 34):

Se a sociedade industrial trouxe no seu bojo elementos como máquinas e ferramentas, trabalhadores especializados, produção em série, energia, entre outros, enfim, tudo voltado para a produção de bens materiais, a sociedade pós-industrial consolida-se na experiência organizacional, no investimento em tecnologia de ponta, nos grupos de especialistas, na produção modular, na informação, isto é, na geração de serviços e na produção e transmissão da informação (Santos, 1990; Zuffo, 1997). Essas transformações ocorreram a partir da década de 50, que assistiu a mais uma significativa ruptura no campo da ciência. É o início da chamada era pós-industrial, quando predominam “... os esforços (científicos, tecnológicos e políticos) no sentido de informatizar a sociedade. (...) descobriu-se que a fonte de todas as fontes chamase informação. (CARVALHO; KANISKI, 2000, p. 34)

O computador foi um significante produto que marcou essa fase, tendo sido o mesmo inserido nos inúmeros seguimentos empresariais, otimizando a comunicação com o mundo. Sobre a era da computação, Manuel Castells (2016, p. 178):

A globalização econômica completa só poderia acontecer com base nas novas tecnologias da comunicação e da informação. Os sistemas avançados de computação permitiam que novos e potentes modelos matemáticos administrassem produtos financeiros complexos e realizassem transações em alta velocidade. Sistemas avançadíssimos de telecomunicações ligavam em tempo real os centros financeiros de todo o mundo. A administração on-line permitia que as empresas operassem no país inteiro e no mundo inteiro. (...) A informática foi essencial para o funcionamento de uma teia mundial de transporte rápido e de alta capacidade de bens e pessoas, estabelecida por transportes aéreos, linhas de navegação transoceânica, estradas de ferro e auto-estradas (CASTELLS, 2016, p.178). 
A sociedade se reinventou diante do surgimento da internet, tendo como reflexo principal a determinação da especialização da mão de obra de forma criteriosa como requisito de inserção ao mercado de trabalho. Diante de tal fato, a era pós-industrial deu margem ao seguimento de prestação de serviços, englobando aquelas pessoas que não possuíam formação superior, dando assim, ensejo a uma oportunidade de crescimento no mercado como um profissional liberal.

É inegável que computadores e máquinas foram popularizados, fazendo parte do cotidiano. Cada vez mais acessíveis, substituíram postos de trabalho que seriam ocupados por humanos, até mesmo na agricultura. Fato esse ocorrido com base no advento da robótica, em virtude das máquinas conectadas à internet capazes de otimizar tempo, produção e informação, como nano e biotecnologia, dentre outros. Contudo, é claramente visível a capacidade de reinvenção da sociedade quando se depara ao desenvolvimento, ao novo. Sobre as transformações, Cláudio Fernandes (on-line):

Como consequências da Revolução Industrial, podemos apontar o desenvolvimento tecnológico acelerado, que caracterizou uma sucessão de etapas evolutivas, como a Segunda Revolução Industrial (desenvolvida no século XIX, seu principal aspecto foi a criação dos motores de combustão interna movidos a combustíveis derivados do petróleo) e a Terceira Revolução Industrial (desenvolvida no século XX e ainda em expansão, seu aspecto principal são os ramos da microeletrônica, engenharia genética, nanotecnologia, entre outros). (FERNANDES, online).

O avanço tecnológico é um caminho sem volta e é incontestável seus benefícios proporcionados ao povo. Mesmo com inúmeros desafios que a sociedade teve e tem de enfrentar para se realocar no âmbito laboral, econômico e social, diante da aderência de tecnologias disruptivas, essas mesmas promoveram a diminuição de distâncias através dos meios de comunicação, tornando possível pessoas se conectarem com outras em todos os continentes do planeta e a propagação de informação em alta velocidade ou em tempo real, expandindo e tornando mais acessível o conhecimento para os menos privilegiados, devido ao menor custo. Krishan Kumar (2013, p. 49) relata:

Muito mais eficientes para ligar o mundo, porém, têm sido as comunicações via satélite (...) A combinação de satélites, televisão, telefone, cabo de fibra ótica e microcomputadores enfeixou o mundo em um sistema unificado de conhecimento. Ela "acabou com a imprecisão da informação. Agora, pela primeira vez, somos uma economia realmente global, porque, pela primeira vez, temos informações compartilhadas de forma instantânea pelo planeta" (Naisbitt 1984:57) (KUMAR, 2013, p. 49). 
$\mathrm{Na}$ seara jurídica, o papel impresso tornou-se arcaico, os processos tornaram-se digitais, o que possibilitou aos advogados peticionaram em diversos processos de cidades diferentes sem a necessidade de se deslocarem até a comarca para realizar um simples protocolo ou até mesmo requerer a cópia de um processo. A virtualização dos processos otimizou o trabalho jurídico, reduziu distâncias e economizou tempo. Além disso, há inúmeros benefícios ao meio ambiente com a redução de papel.

No mesmo sentido, e mais atual, diante da grave crise mundial na saúde, vivenciada desde março de 2020 no Brasil, o teletrabalho se tornou presente na vida de inúmeros brasileiros. Em razão do isolamento social, os trabalhadores ficaram impossibilitados de se deslocarem aos seus locais de trabalho, o que foi possível desempenhar suas atividades diretamente de casa, por meio de várias tecnologias disruptivas já mencionadas e implementadas ao longo dos anos, como a eletricidade, internet e computadores. Outrossim, a redução de distâncias, o tempo em virtude de jornadas de trabalho flexíveis, os custos, as fontes de energia como combustível, dentre outros, são apenas alguns benefícios que o teletrabalho proporciona.

A automação está presente, agora não só em atividades manuais, mas também em atividades intelectuais. Tal disrupção já faz parte da vida dos brasileiros, e, mais uma vez, foi possível visualizar a rápida reinvenção da sociedade para se conectar ao advento de mais uma tecnologia. Dito isso, Domenico de Masi (2014, p. 16-17) expõe:

\begin{abstract}
O mercado de trabalho é implacável: num dos pratos da balança vão-se empilhando os desocupados à cata de emprego; do outro prato vão sumindo os postos de trabalho disponíveis. (...) No entanto, do outro lado da balança os postos disponíveis crescem a um ritmo muito mais lento do que o número de postulantes. Aqui também os motivos são claros. As novas tecnologias conseguem cada vez mais suplantar o trabalho humano, não só nas atividades físicas dos serventes como também nas intelectuais, dos profissionais liberais; os progressos organizacionais conseguem combinar sempre melhor os fatores produtivos de movo a obter um número crescente de produtos por um número decrescente de horas trabalhadas; a globalização permite instalar as fábricas no Terceiro Mundo e atingir bens e serviços em países ainda que muito distantes, evitando produzi-los no lugar (...). (DE MASSI, 2014, p.16-17)
\end{abstract}

Nesse cenário, importante abordar algumas tecnologias disruptivas que estão por vir, algumas já presentes no cotidiano brasileiro, e seus possíveis reflexos sociais e econômicos.

\title{
3 TECNOLOGIAS DISRUPTIVAS E SEUS REFLEXOS
}


As tecnologias disruptivas refletem diretamente na sociedade. Com o advento dessas transformações foi possível otimizar tempo e riqueza. Apesar dos inúmeros avanços almejados com a tecnologia, esse marco histórico possui seu lado sombrio, de instabilidade e incertezas, considerando que estaríamos diante do caráter de dois gumes da modernidade (GIDDENS, 1990, p.15).

A perspectiva é de que um grande desafio está por vir a ser enfrentado pelo mercado de trabalho, servindo de alerta diante da nova era de disrupção tecnológica. Citam-se como exemplo algumas tecnologias que afetam diretamente postos de trabalho, como a automação veicular e a adoção de inteligência artificial nas empresas.

A economia compartilhada ou colaborativa permite redefinir tempo e espaço possibilitando negociações mais práticas por meio da internet. Esse design permite o uso de produtos pertencente a outras pessoas, sem precisar adquiri-los, partindo da premissa de apenas saciar necessidades esporádicas.

A despeito não se referir uma tecnologia propriamente dita, a economia compartilhada introduziu um novo molde de negócios tecnológicos, englobando, além de compartilhamento de produtos, o parâmetro da negociação sem o intermédio de um vendedor. Por meio de aplicativos ou outras plataformas digitais, as empresas anunciam seus produtos, podendo ter um alcance de venda mundial, e nesse design, o próprio consumidor negocia suas transações. Conforme Dora Kaufman (2013, online):

O consumidor atual quando se vê diante da necessidade de exercer uma preferência de qualquer natureza, em geral, consulta as plataformas de busca, acessa redes sociais, sites, editorias e blogs especializados. Estamos lidando com uma sociedade emergente baseada na informação e no conhecimento, que se organiza de uma maneira totalmente distinta da sociedade industrial constituída a partir da Primeira e Segunda Revoluções Industriais (séculos XVIII, XIX e XX). A circulação da informação não obedece às mesmas regras que a circulação das mercadorias, em termos de propriedade, de determinação do valor, da natureza das transações comerciais, da lógica do consumo. O filósofo Michel Puech (2008) crê que o trabalho e a posse dos bens materiais não são mais o centro da estrutura social, e que o contexto geral do intercâmbio social e econômico, que foi competitivo na era industrial, será colaborativo na era pós-industrial. O autor compartilha a crença de que está em curso uma nova revolução industrial, onde a "mercadoria" informação não funciona como as demais mercadorias, não gera um mercado de escassez de bens regulados pela oferta e demanda, refletida no preço. Pelo contrário, a nova economia caracteriza-se pela abundância, não importa quantas vezes copiamos e enviamos aos amigos um arquivo digital com música, ele continua disponível e reprodutível. (KAUFMAN, 2013, online) 
O modo de vida colaborativo vem sendo demonstrado como um meio de baixo custo de compartilhamento de filmes (Netflix), livros (Amazon), músicas (Spotify), transporte (Uber), e hospedagem (Airbnb), por exemplo. A Netflix dentre outras plataformas de streaming acabaram com a figura das locadoras de DVD's, da mesma forma livrarias estão cada vez mais desertas com a possibilidade de você ter um livro em poucos minutos em seu computador e ainda ajudando o meio ambiente com a redução de papel. Merece destaque da mesma forma a redução drástica de venda de CD's quando se pode ter a música que deseja de maneira mais rápida em seu celular por meio do Spotify. A chegada da Uber ao Brasil, a qual protagonizou diversas polêmicas envolvendo taxistas, proporcionou ao cidadão a optar por pagar bem menos em um deslocamento. É importante mencionar também o grande impacto no setor hoteleiro ocasionado pela plataforma Airbnb, pois possibilitou uma hospedagem bem mais econômica, fato esse provocado pela ausência de funcionários, impostos e demais gastos que um hotel necessita ter para manter-se em funcionamento.

A automação veicular é mais um exemplo de tecnologia disruptiva que já é realidade em alguns países, como nos Estados Unidos. Um destaque importante aos carros autônomos é que eles são elétricos, e uma recarga completa seria bem mais em conta que o abastecimento com combustível, seja álcool, gasolina ou diesel, tendo uma excelente autonomia.

Por se deslocarem sem a necessidade de motorista, se torna mais uma tecnologia que gera alerta a sociedade. É possível chegar ao ponto de ter-se uber, taxi, ônibus e trens sem a necessidade de motorista, sendo guiados por meio de um sistema que, a priori, traz bastante segurança, por ser capaz de manter distancias adequadas dos demais carros, reduzir velocidade quando determinado pela da sinalização de trânsito, além de percorrer trajetos mais curtos reduzindo o tempo deslocamento. Nesse sentido Kai-Fu Lee (2019, p. 125):

Os veículos autônomos estão a caminho de se tornarem, de alguma forma, muito mais seguros do que os veículos dirigidos por seres humanos, e a implantação generalizada da tecnologia reduzirá drasticamente essas fatalidades. Também levará a enormes aumentos na eficiência das redes de transporte e logística, ganho que ecoarão em toda e economia. Porém, paralelamente às vidas salvas e à produtividade obtida, haverá outros casos em que empregos ou até vidas serão perdidas devido à mesma tecnologia. Para começar, os motoristas de táxi, caminhão e ônibus e entregadores em geral terão pouca utilidade em um mundo de direção autônoma. Também será inevitável o mau funcionamento em veículos autônomos que causarão colisões. Haverá circunstâncias que forçarão esses veículos a tomarem decisões éticas angustiantes, como se deverão virar para a direita, com 55\% de chance de matar duas pessoas, ou virar para a esquerda, com $100 \%$ de chance de matar uma. (LEE, 2019, p. 12) 
A impressora 3D é mais uma espécie de tecnologia disruptiva que causa uma alerta para a sociedade. O advento tecnológico trouxe ao indivíduo um leque de possibilidades através dessa ferramenta. Por meio dela é possível a impressão de inumeráveis objetos e a perspectiva é de que possamos imprimir carros, armas de fogo e até mesmo uma outra impressora 3D. Aos passar dos anos ela se tornará cada vez mais acessível à população, e é isso que causa inquietação a nossa sociedade. Nesse sentido, Klaus Schwab (2018, p. 2018):

\begin{abstract}
Os processos de impressão em 3D existem há mais de 25 anos. As impressoras atraíram mais atenção recentemente, no entanto, porque se tornaram menores, mais baratas, melhores e mais versáteis. Os produtos agora têm propriedades materiais muito complexas, acabamentos detalhados e usinagem de precisão. Apesar de muito associarem a impressora 3D a pequenos objetos de plástico, nós agora podemos imprimir diversos materiais, como metal, cerâmica e concreto, bem como materiais modernos, incluindo o grafeno (fino, forte e flexível), o carboneto de tungstênio (que pode suportar enormes cargas, usado por moinhos ou brocas, por exemplo) e materiais ecológicos de base biológica (como alternativas para o plástico, bem como os alimentos, o macarrão por exemplo). A impressora em 3D com diversos materiais já existe e provavelmente se tornará comum (SCHWAB, 2018, p. 208).
\end{abstract}

Apesar de a mesma proporcionar o acesso a bens e produtos por um menor custo, preocupante se torna o impacto social e econômico causado, uma vez que tornará impossibilitado a comercialização de inúmeros produtos, por termos a possibilidade de imprimirmos o que quisermos dentro da nossa casa por meio da nossa própria impressora 3D. Conforme Jereny Rifkin (2016, p. 115):

A nova revolução da impressão 3 D é um exemplo de "produtividade extrema". Ainda não está totalmente consolidada, mas à medida que evolui, tende inevitavelmente a reduzir o custo marginal para próximo a zero, eliminar o lucro e tornar a comercialização no mercado desnecessária para muitos (embora não todos) produtos). A democratização da manufatura significa que cada pessoa e, oportunamente todas, terá acesso aos meios de produção, tornando irrelevante a questão de quem deve ter a posse e o controle dos meios de produção e, com isso, do capitalismo (RIFKIN, 2016, p. 115)

A impressora 3D causa uma sensação de ilimitada proporção de impressões. A impressão de órgãos para transplante em humanos e próteses personalizadas é uma das inovações que nos aguarda. A impressão de casas também está no leque de possibilidades.

Diante de todas as imagináveis coisas que a impressora 3D pode prover, a polarização dessa ferramenta causa alarmes para o futuro. Apenas alguns exemplos acima citados afetariam diretamente montadoras de veículos e a construção civil. Haveria ainda, os efeitos socioeconômicos em razão do menor número de empregos e menor circulação de produtos, já que tudo que o indivíduo necessitaria, bastaria imprimir. 
Dito isso, importante abordar possibilidade de qual seria o dever do Estado visando associar o advento tecnológico e a garantia dos direitos fundamentais sociais inerentes ao homem diante da eminente crise econômica e social.

\section{O DEVER DO ESTADO}

Sabe-se que a nossa Constituição Federal de 1988 (CF/88) possui em seu corpo um leque de valores tidos como direitos fundamentais, direitos esses inerente a todos os cidadãos e que devem ser garantidos para que a dignidade da pessoa humana seja resguardada, ou seja, para que seja garantido o mínimo existencial ao ser humano, conforme transcreve:

Art. $1^{\circ}$ A República Federativa do Brasil, formada pela união indissolúvel dos Estados e Municípios e do Distrito Federal, constitui-se em Estado Democrático de Direito e tem como fundamentos: (...) IV - os valores sociais do trabalho e da livre iniciativa. (grifo nosso)

Art. $6^{\circ}$ São direitos sociais a educação, a saúde, a alimentação, o trabalho, a moradia, o transporte, o lazer, a segurança, a previdência social, a proteção à maternidade e à infância, a assistência aos desamparados, na forma desta Constituição. (Redação dada pela Emenda Constitucional n 90, de 2015) (grifo nosso)

Art. 170. A ordem econômica, fundada na valorização do trabalho humano e na livre iniciativa, tem por fim assegurar a todos existência digna, conforme os ditames da justiça social, observados os seguintes princípios: (...) VIII - busca do pleno emprego. (grifo nosso)

Diante do que foi abordado, os direitos de proteção ao trabalho e busca do pleno emprego restam ameaçados em razão da robotização que estará presente cada vez mais de forma significativa no contexto social. Postos de trabalho poderão ser substituídos por alguma tecnologia disruptiva ou funções serem extintas, tornando cada vez mais precárias as relações de trabalho e o trabalhador cada vez mais vulnerabilizado. Marmelstein $(2016$, p. 18) traz seu conceito de direitos fundamentais como:

Normas jurídicas, intimamente ligadas à ideia de dignidade da pessoa humana e de limitação do poder, positivadas no plano constitucional de determinado Estado Democrático de Direito, que, por sua importância axiológica, fundamentam e legitimam todo o ordenamento jurídico (MARMELSTEIN, 2016, p. 18).

Em face de tantas transformações ocorridas no contexto social, pelo advento tecnológico, a concretização dos direitos fundamentais sociais de proteção ao trabalhador resta abalada. Por dar ensejo à substituição cada vez maior da mão de obra humana por tecnologias, em razão do menor custo, o índice de desemprego se mantém crescente. 
Em razão da iminente crise social e econômica, o Estado deve se posicionar a fim de evitar um colapso nas relações de labor, garantindo o direito social do pleno emprego à humanos. As transformações ocorridas ao longo dos anos foram cruciais para o desenvolvimento da sociedade como um todo. Porém, a perspectiva é de que, se não houver a cautela devida, a Revolução 4.0 trará mais malefícios que benefícios a classe trabalhadora, valorizando apenas os mais favorecidos e em situação de superioridade na relação de emprego.

Como já abordado, as novas tecnologias que estão por vir, algumas já realidade no Brasil, porém outras presentes apenas em outros países, refletem diretamente na possível extinção de alguns cargos de trabalho. E tais possíveis extinções atingem tanto as atividades manuais como as intelectuais. Nesse sentido, Rodrigo Paiz Basso (2019, p. 26):

As grandes mudanças trazidas pela Rovolução 4.0 afetam e afetarão a forma como o
trabalho é desenvolvido em todo o mundo, sendo que isso já pode ser percebido,
mesmo que sutilmente, no dia a dia, sem que as pessoas se deem conta de quão
próximas estão essas inovações. Exemplos disso são os sistemas de inteligência
artificial que estão presentes em diversas empresas (Siri - apple, Bia - Bradesco,
Aura - Vivo, só para ilustrar). Aplicativos e softwares de todos os tipos já fazem
parte do cotidiano: redes sociais, serviços bancários, de transporte (Uber), de
gerenciamento de processos jurídicos (Themis), entre inúmeros outros. (BASSO,
2019, p. 26).

A preparação da população para o futuro mercado de trabalho é uma das possíveis soluções a serem apresentadas pelo Estado. A mudança de grade nas escolas e universidades, a preparação para o surgimento de novas profissões e a busca pelo equilíbrio entre as inserções tecnológicas no mercado de trabalho e a empregabilidade são os principais desafios a serem enfrentados.

Preparar o país para receber tecnologias de primeiro mundo também poderá estar no rol de ações que deverão ser tomadas, com alterações legislativas que não desfavoreçam a figura do trabalhador, buscando sempre preservar seus direitos fundamentais e efetivar o texto constitucional, dando ênfase as principais consequências que podem ocorrer por essa revolução.

Buscar apenas o que há de melhor que o advento tecnológico tem a oferecer a sociedade, como assim muito fez nas Revoluções Industriais, separando tempo e espaço e diminuindo distâncias. Porém, não se sabe mais como será o comportamento dos indivíduos ao passar dos anos.

Não só a população, o trabalho e a economia necessitarão de mudanças legislativas, mas as tecnologias propriamente ditas necessitam de uma regulamentação para circularem em 
sociedade, e como se portar diante de algum equívoco. Uma das mais corriqueiras circunstâncias na qual necessitará uma atenção do Estado seria, por exemplo, a responsabilidade em caso de acidente envolvendo carros autônomos, seria o proprietário do carro punido? Ou a fabricante? Ou no caso seria o responsável pelo sistema? Ou seria o Estado por permitir a circulação desse modelo de veículo na sociedade?

O mesmo exemplo se enquadra quanto as impressoras 3D. Alguém portando uma arma de fogo oriunda de uma impressora 3D responderia por porte ilegal de armas? E quem seria o responsável? O dono da arma? O dono da impressora que a imprimiu? O criador do arquivo da modelagem tridimensional? A fabricante da impressora que admitiu a impressão desse tipo de arquivo? E em relação aos direitos autorais sobre o arquivo, a pirataria poderá estar presente violando a propriedade intelectual dos autores. Todos esses seriam questionamento a serem respondidos por meio de legislação.

Podemos visualizar que a sociedade sempre foi capaz de se reinventar quando se deparou com o desenvolvimento. O lado otimista é que haverá a criação de novas profissões, e o que antes ocupavam cargos que foram autonomizados pela tecnologia, estarão preparados para exercerem essas novas funções. Será através da educação que os indivíduos se reencontrarão no mercado de trabalho. As modificações desde o ensino fundamental até a universidade capacitarão os trabalhadores para enfrentarem a nova era, garantindo sua subsistência.

A criação de novos impostos para as empresas também se torna uma possibilidade a fim de não abdicarem da mão de obra humana por robôs. Novos tributos seriam uma espécie e compensação fiscal pelo desemprego e desigualdades, pois uma vez que os posto de trabalho se encontram cada vez mais escassos, os indivíduos, mesmo qualificados, se submetem ao subemprego para garantir o mínimo.

Com o poder de compra reduzido, devido ao recebimento de baixos salários auferidos pelos subempregos, um estilo de vida mais modesto poderá ser realidade para os brasileiros daqui uns anos. Consequentemente os indivíduos quem ganharão menos, gastarão mesmo, e tal impacto não afetará somente o âmbito social, mas também a economia, com menos pessoas comprando, maior será a inflação.

Preservar os direitos fundamentais sociais do trabalho será um grande desafio a ser enfrentado pelo Estado e pela população, em razão da iminente precarização das profíssões e mão de obra humana substituída pela robótica. 
Preparar o país para esse novo cenário econômico com legislação eficazes e que realmente sejam efetivadas, com tributação às empresas como forma de incentivo a contratação de mão de obra humana, mudanças normativas quando as grades escolares, desde o ensino fundamental até o ensino superior, garantindo assim o enquadramento às novas modalidades de profissões que o mercado ofertará e normas que regulem as tecnologias inseridas no contexto social são apenas alguns pontos apresentados a serem efetivados pelo Estado, exercendo seu papel de garantidor da Constituição.

\section{CONCLUSÃO}

Este trabalho buscou demonstrar uma evolução histórica de tecnologias nas quais foram inseridas na sociedade ao longo dos anos, quais foram seus reflexos, que abalaram principalmente as relações de trabalho, e como foi o comportamento humano frente essas transformações. Demonstraram-se, ainda, algumas inovações tecnológicas que estão por vir, algumas já presentes de forma tímida, e quais seriam seus reflexos sociais, econômicos e laborais.

Abordou-se qual seria o dever do Estado, buscando como principal fim a contenção do desemprego e proteção dos direitos sociais, diante da predominante fragilidade das relações de labor, decorrentes da adoção de automação de profissões, refletindo não só no âmbito social, como também no âmbito econômico.

A reorganização da sociedade e restruturação da economia frente as novas tecnologias que serão adotadas serão cruciais para a diminuição os índices de desemprego. A sociedade poderá se reorganizar por meio da adoção de medidas para a preservação de direitos sociais do homem mediante políticas públicas a serem instituídas pelo Poder Público, como capacitar os indivíduos para a chegada de novos postos de emprego, desde o ensino fundamental ao superior e regulamentar tais ferramentas, tanto pelo seu uso, como suas responsabilidades.

Além do mais, deverá o Estado trabalhar juntamente com a iniciativa privada, por meio de políticas de incentivo à contratação da mão de obra humana através de possíveis tributações, sempre buscando conciliar as garantias constitucionais e as disrupções, uma vez que não podemos retardar ou estagnar o avanço tecnológico. 
Embora todo o contexto tecnológico inserido e seus reflexos que abalaram as relações de labor, é inquestionável seu papel fundamental para a evolução humana diante dos seus inúmeros benefícios. Com a preservação da dignidade da pessoa humana diante da garantia da efetivação constitucional por meio da preservação dos direitos fundamentais sociais e a postura conciliadora com o advento de novas tecnologias, o país estará apto a receber o desenvolvimento, não ficando para trás em relação aos demais países. O progresso desenfreado está por vir e só resta estar preparado para recebê-lo no futuro.

\section{REFERÊNCIAS BIBLIOGRÁFICAS}

BASSO, Rodrigo Paiz. Revolução 4.0: uma discussão acerca do papel do Estado e sua relação com os princípios constitucionais dentro do contexto jurídico trabalhista contemporâneo. 2019. 60f. Monografia (Graduação em Direito). Universidade de Passo Fundo, Passo Fundo, RS, 2019. Disponível em: http://repositorio.upf.br/bitstream/riupf/1762/1/PF2019Rodrigo\%20Paiz\%20Basso.pdf. Acesso em: 15 jun. 2021.

BAUMAN, Zygmunt. Tempos Líquidos. 1 ed. Rio de Janeiro: Zahar, 2007.

BRASIL. Constituição da República Federativa do Brasil de 1988. Disponível em: http://www.planalto.gov.br/ccivil_03/constituicao/constituicao.htm. Acesso em: 27 mai. 2021.

CARVALHO, Isabel Cristina Louzada; KANISKI, Ana Lúcia. A sociedade do conhecimento e o acesso à informação: para que e para quem. Ciência da informação, v. 29, n. 3, p. 33-39, 2000 . https://www.scielo.br/j/ci/a/j9RG4gLkBGTtqqfQ6LBxMwy/?lang=pt\&format=pdf. Acesso em: 14 jun. 2021.

CASTELLS, Manuel. A sociedade em rede. Trad. Roneide Venâncio Majer. $17^{\mathrm{a}}$ edição, revista e ampliada. São Paulo: Paz e Terra, 2016.

CAVALCANTE, Zedequias Vieira; SILVA, Mauro Luis Siqueira da. A importância da revolução industrial no mundo da tecnologia. In: VII Encontro Internacional de Produção Científica. Anais eletrônicos. Maringá: Cesumar, 2011. Disponível em: https://www.unicesumar.edu.br/epcc-2011/wpcontent/uploads/sites/86/2016/07/zedequias_vieira_cavalcante2.pdf. Acesso em: 14 jun. 2021. 
DE MASI, Domenico. O Futuro do Trabalho: fadiga e ócio na sociedade pós-industrial. Tradução: Yadyr A. Fugueiredo. 11 ed. Rio de Janeiro: José Olympio, 2014. Disponível em: https://filosoficabiblioteca.files.wordpress.com/2020/04/de-masi-domenico.-o-futuro-dotrabalho-1.pdf. Acesso em 17 jun. 2021.

FERNANDES, Cláudio. Revolução Industrial. Disponível em: https://www.historiadomundo.com.br/idade-moderna/revolucao-industrial.htm. Acesso em: 18 jun. 2021.

GIDDENS, Anthony. As Consequências da Modernidade. 5 ed. São Paulo: Unesp, 1990.

HARARI, Yuval Noah. 21 lições para o século 21. 1 ed. São Paulo: Companhia das Letras, 2018.

KAUFMAN, Dora. Arquiteturas Colaborativas Digitais. In: $37^{\circ}$ Encontro Anual da ANPOCS. Anais eletrônicos. Águas de Lindoia, São Paulo, 2013. Disponível em: https://www.anpocs.com/index.php/papers-37-encontro/st/st09/8438-arquiteturas-

colaborativas-digitais-um-estudo-das-redes-empresa-consumidores-no-brasil/file. Acesso em: 18 jun. 2021.

KUMAR, Krishan. Da sociedade pós-industrial à pós-moderna: novas teorias sobre o mundo contemporâneo. 2 ed. São Paulo: Zahar, 1997.

LEE, Kai-Fu. Inteligência Artificial: como os robôs estão mudando o mundo, a forma que amamos, nos comunicamos e vivemos. Tradução: Marcelo Barbão. 1 ed. Rio de Janeiro: Globo Livros, 2019.

MARMELSTEIN, George. Curso de direitos fundamentais. 6 ed. São Paulo: Atlas, 2016.

RIFKIN, Jeremy. Sociedade com custo marginal zero. 1 ed. São Paulo: M. Books do Brasil, 2016.

SANSON, Cesar. Trabalho e subjetividade: da sociedade industrial à sociedade pós-industrial. Cadernos IHU, p. 1-63, 2009. Disponível em: https://acervodigital.ufpr.br/bitstream/handle/1884/24122/VERSAO FINAL BANCA.pdf?se quence=1\&isAllowed=y. Acesso em: 14 jun. 2021.

SCHWAB, Klaus. Aplicando a Quarta Revolução Industrial. Tradução: Daniel Moreira Miranda. 1 ed. São Paulo: Edipro, 2018. 